\title{
New research and development of titanium production and application in the CIS.
}

\author{
A. Alexandrov \\ Interstate Association Titan \\ Moscow, Russian Federation \\ isat91@mail.ru
}

\begin{abstract}
$\underline{\text { Abstract }}$
Review of the titanium industry in the CIS in research, production and application of titanium over the past four years. Plans and forecasts of development.
\end{abstract}

\section{Introduction}

The main achievement of the past four-year period for titanium market in CIS is the saving of output and consumption of titanium mill product at enough high level in volume: production of $32-36$ thousand tons per year, consumption at domestic market is about $10-12$ thousand tons per year.

What the titanium marked is based on? High share of alloys in total volume of titanium product. As a result, the primary markets of our titanium are aerospace, shipbuilding and other markets of critical application. These markets show high stability for 10 last years.

In general, supplies of commercially pure titanium are based mainly on cooperation of the VSMPO-AVISMA Corporation with Allegheny Technologies within the joint project Unity.

\section{Sponge titanium}

Sponge titanium manufacturing in Ukraine, Russia and Kazakhstan is characterized by stable high level of quality. Now, high quality sponge titanium has essential advantages in the market. Therefore, due to the higher demand the output volume in all the enterprises of CIS has increased noticeably.

Zaporozhe Titanium magnesium plant (ZTMK) in 2018 has produced about 8 thousand tons of sponge titanium.

AVISMA ramped up the production to maximum. Now it produces about 44 thousand tons per year. About 2 thousand tons per year are produced by magnesium plant in Solikamsk.

Ust Kamenogorsk Titanium magnesium plant (UKTMK) has produced about 18 thousand tons in 2018 and aims at introduction of additional capacities this year. At this Company a radically new bipolar electrolyzer for magnesium electrolysis was developed and tested, which will allow to reduce the electrical power consumption by $20 \%$ in comparison with the existing technology.

\section{Melting}

The general volume of melted ingots in CIS has increased up to 68 thousand tons.

Two new skull furnaces with pour weight up to 7 tons for highly alloyed titanium alloys with high homogeneity are commissioned at VSMPO-AVISMA Corporation, without any inclusion, that is provided with this technology. VSMPO-AVISMA carried out the product certification obtained due to use of skull melting by leading manufacturers of aero-engines.

Ingot manufacturing practice by skull melting has a range of important advantages:

- high homogeneity;

- melting and casting processes are performed separately;

- refining power;

- no limits of dimensions and amount of using scrap.

Chepetsk Mechanical Plant (CMP), the Glazow city, mastered the technology of ingots melting with weight up to $1100 \mathrm{~kg}$ of orthoalloy of titanium-aluminum-niobium. Pilot batches of $450 \mathrm{~mm}$ dia triple VAR ingots were manufactured [1].

\section{Mill products}

Mill products output in CIS has reached 36 thousand tons.

VSMPO-AVISMA Corporation is the main manufacturer of rolled titanium and titanium alloys products on the territory of the former USSR. The corporation is one of the few of vertically integrated organizations, that is a leader in the global high-tech market for titanium products: from titanium ingots to all types of semi-finished products of titanium alloys, and it almost completely satisfies customers of titanium in Russia in all industries from aviation, aerospace and shipbuilding to power industry and medicine, providing a full range of titanium semi-finished products and die forgings.

(C) The Authors, published by EDP Sciences. This is an open access article distributed under the terms of the Creative Commons Attribution License 4.0 (http://creativecommons.org/licenses/by/4.0/). 
In recent years the Corporation actively diversifies its manufacture and expands the product portfolio.

At the VSMPO-AVISMA Corporation a new 4000 ton forging press was commissioned. As a result, the number of conversion presses at the enterprise reached 8 pieces. Development of forging capacity is extremely important due to the fact that it is an essential production stage for the transition from ingot to all types of semi-finished products.

Also a new complex of equipment was installed for manufacture of rolled rings with diameter of up to $3500 \mathrm{~mm}$. The complex includes 8000 tons press for upsetting and punching of stock, rings rolling mill, two expanders and furnaces for preheating and heat treatment.

Table 1. Available rings manufacturing capabilities

\begin{tabular}{|l|l|}
\hline Range & $\begin{array}{l}\text { Outer dia. up to } 3500 \mathrm{~mm}, \text { height up to } 800 \\
\mathrm{~mm}\end{array}$ \\
\hline Material & Any titanium alloys \\
\hline Heat treatment & Annealing, solution heat treatment \\
\hline Machining & $\begin{array}{l}\text { Rough machining and near net shape } \\
\text { machining }\end{array}$ \\
\hline $\begin{array}{l}\text { Testing and } \\
\text { Inspection }\end{array}$ & Destructive and Non-Destructive \\
\hline
\end{tabular}

A joint enterprise of VSMPO-AVISMA Corporation and Arconic has started operation. As a result, a duplicating chain of production of large die forgings of critical application was formed, which provides a guaranty of reliable supplies of important items for leading aircraft Customers.

The production of flat-rolled products increases. A new equipment was commissioned at the VSMPO-AVISMA Corporation that includes three plate straightening machines for thick plate heating. New auxiliary equipment was introduced to increase the output of thin sheet of high-alloyed titanium alloys.

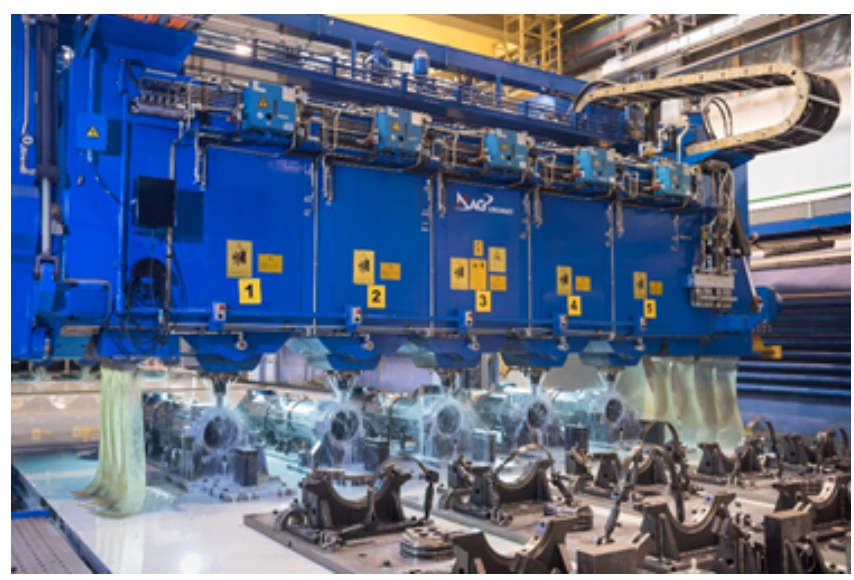

Pic. 1 New Cincinatti machine at the VSMPO-AVISMA Corporation

VSMPO-AVISMA Corporation increased its machining capacity. Modern machines for rough and semi-finish machining of contoured parts_were installed. Such machining allows to keep significant volume of high quality scrap to involve them in melting, that considerably reduces the product cost.

For development of machining capacity, the second joint enterprise Ural Boeing Manufacturing was started in 2018 in Titanium Valley in Verkhnyaya Salda.

\section{Engineering}

There are many news from the engineering companies supporting the Ti industry. The highest interest is in the significant progress in the development of a wide range of equipment for additive technologies and HIP.

The new PREP units, developed and manufactured by the «Center of Electron-beam technologies» Company (CEBT) are able to spray a titanium stock that is run up at a speed of $40000 \mathrm{rpm}$ into the highest quality fine Ti powders that are well applicable for Additive Manufacturing. 


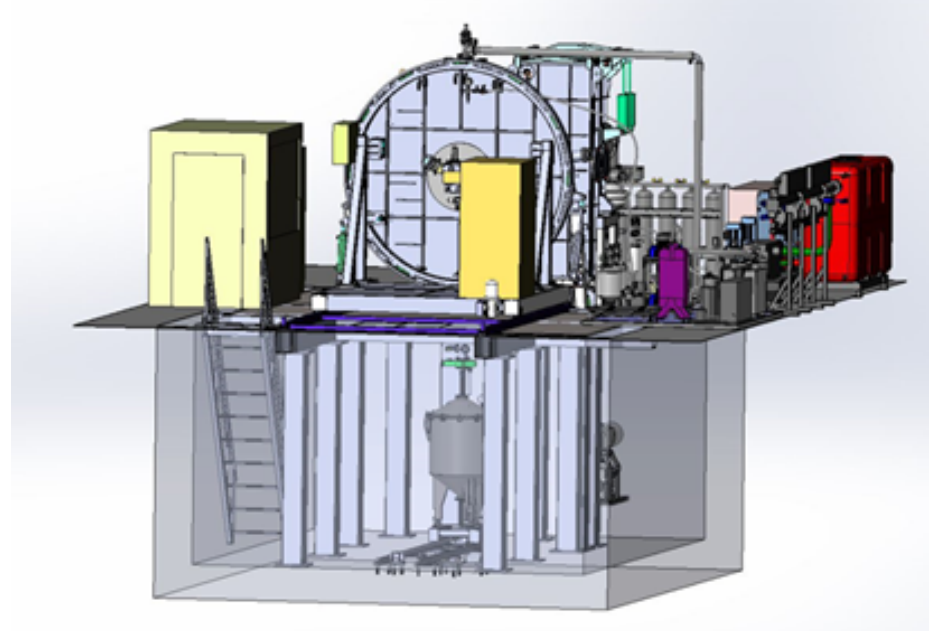

Pic.2 PREP 2.7/40T «Plasma rotating electrode process Ti»

This company has also developed the units «for vacuum filling and sealing of capsules» for subsequent HIP, units of vacuum outgassing of powders for additive manufacturing and elimination of oxygen pick up, units of electrostatic separation removing ceramic inclusions and units for ultra-sonic screening of metal powders with magnetic separation.

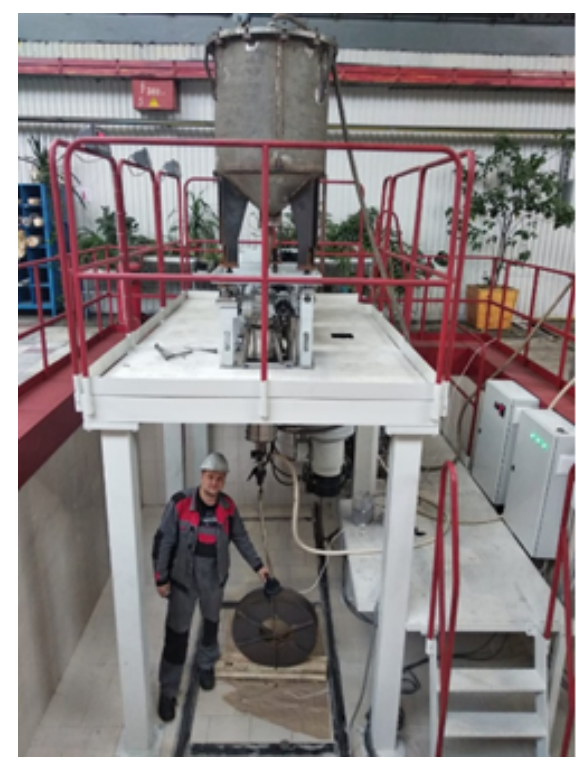

Pic.3 VUF 60/1500 System for hot vacuum outgassing and vacuum filling of powder into capsules for HIP

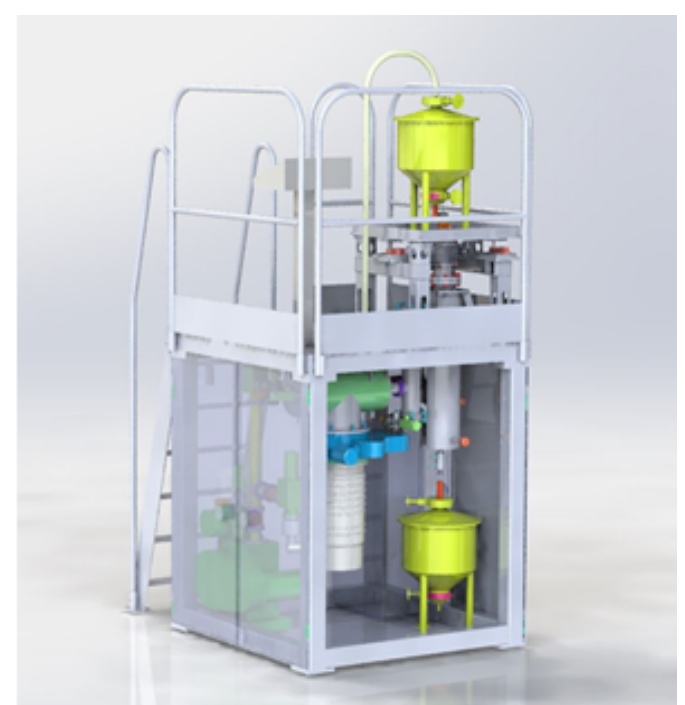

Pic.4 VUD 60/1500 System for vacuum degassing of powders for additive manufacturing and HIP 


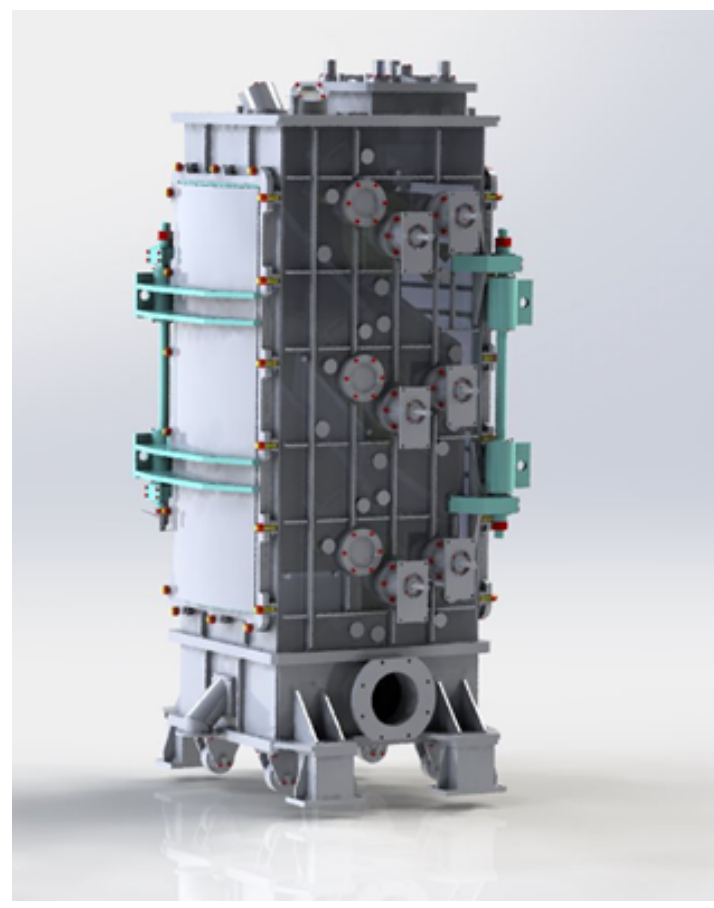

Pic.5 SVES 3/500 «Vacuum Electrostatic Separator»

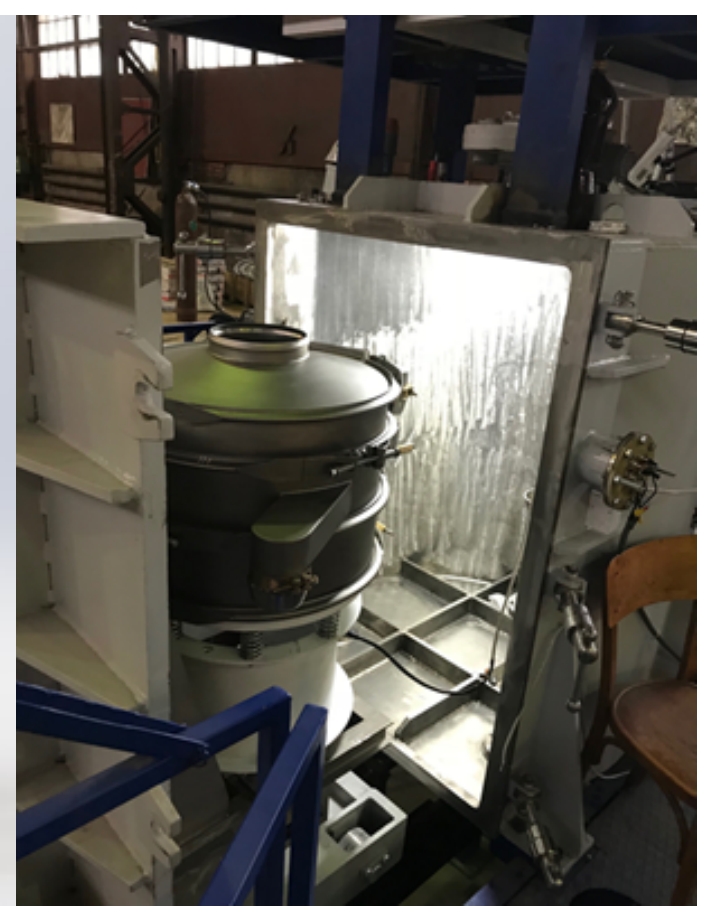

Pic.6 VUS +-3/20/600 Vacuum unit for sieving and magnetic separation

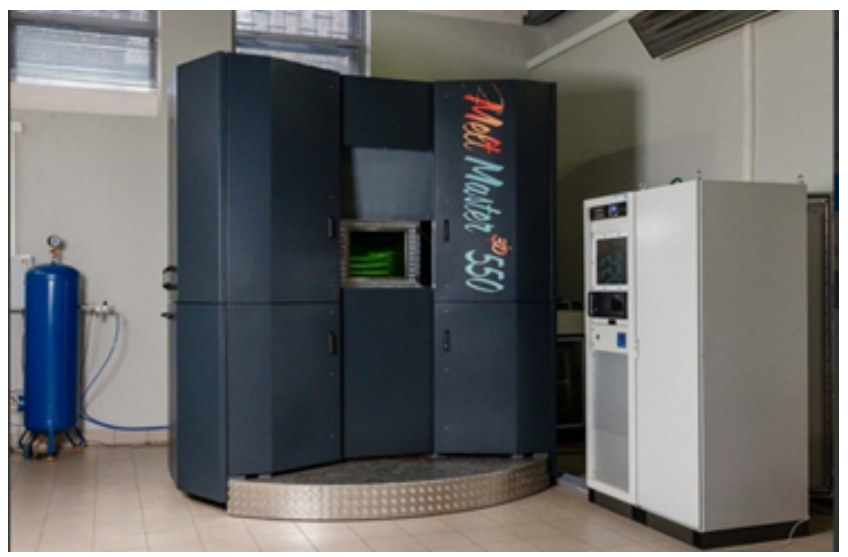

Pic.7 3D printer MeltMaster ${ }^{3 D_{550}}$

Modern 3D printers have been developed in Russia. The unit developed by the NPO "TSNIITMASH", working on SLM method, has following specifications.

Table 2. 3D MeltMaster ${ }^{3 \mathrm{D}} 550$ printer technical characteristics

\begin{tabular}{|c|c|c|c|c|}
\hline Unit & $\begin{array}{c}\text { Plot area dimension, } \\
\mathrm{mm}\end{array}$ & $\begin{array}{c}\text { Laser, number, } \\
\text { pcs. / power, } \mathrm{kW}\end{array}$ & $\begin{array}{c}\text { Plot rate, } \\
\mathrm{cm}^{3} / \mathrm{h}\end{array}$ & $\begin{array}{c}\text { One layer } \\
\text { gauge, } \mu \mathrm{m}\end{array}$ \\
\hline MeltMaster $^{3 \mathrm{D}} 550$ & $550 \times 450 \times 450$ & $1 / 1$ & $15-100$ & $20-250$ \\
\hline
\end{tabular}

Working on SLS method printer is successfully developed at the Ural State University.

In Saint-Petersburg the «ILIST» Company developed a whole family of printers, working by the DMD method.

\section{Powders production}

«Polema» Company has made significant investments in production of powders from many materials, including titanium. Company uses plasma spheroidization of titanium powders, obtained by the method of recovery of oxide raw material with calcium hydride.

Stupino Metallurgical Company (CMK) became the first industrial manufacturer of spherical titanium powders for additive technologies, including powders of critical application. These developments were based on the significant experience of production of 
spherical powders for HIP technologies and on the basis of total redesign of one of their PREP units carried out by the «Center of Electron-beam technologies» Company, as a result, CMK became a serial supplier of titanium powders for different purposes.

The distribution of powder fractions, produced on the new PREP unit, looks in this way:

Table 3. Powder fractional composition, obtained on the modern PREP unit

\begin{tabular}{|c|c|c|c|c|}
\hline Material & $15-50 \mu \mathrm{m}(\%)$ & $50-75 \mu \mathrm{m}(\%)$ & $75-104 \mu \mathrm{m}(\%)$ & $\geq 104 \mu \mathrm{m}(\%)$ \\
\hline Ti-6Al-4V powder & 26 & 52 & 17 & 5 \\
\hline
\end{tabular}

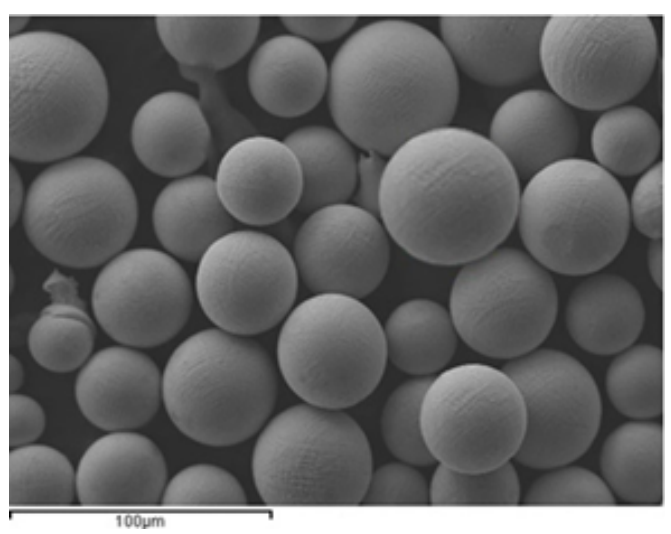

Pic.8 PREP powders

\section{Material science}

Researches are conducted on development of new hot-resistant and functional alloys and methods of their processing. In the group of hot-resistant alloys, ortho-alloys based on $\mathrm{Ti}_{2} \mathrm{AlNb}$, alloys based on $\mathrm{Ti}_{3} \mathrm{Al}$ and alloys with intermetallic hardening are considered as prospective.

Table 4. Physical and chemical characteristics of alloys on the basis of Ti3Al

\begin{tabular}{|c|c|c|c|c|c|c|c|}
\hline Alloy & $\begin{array}{c}\text { Content } \\
\mathrm{Nb}, \% \\
\text { mass. }\end{array}$ & $\begin{array}{c}\text { Density, } \\
\mathrm{g} / \mathrm{cm}^{3}\end{array}$ & \multicolumn{2}{|c|}{$\begin{array}{c}\text { Specific strength, } \\
\mathrm{MPa} \mathrm{cm} / \mathrm{g}\end{array}$} & $\begin{array}{c}\text { Elongation } \\
20^{\circ} \mathrm{C}, \%\end{array}$ & \multicolumn{2}{|c|}{$\begin{array}{c}\text { Specific module of } \\
\text { elasticity E/d, MPa } \\
\mathrm{cm}^{3} / \mathrm{g}\end{array}$} \\
\cline { 4 - 8 } & $-200^{\circ} \mathrm{C}$ & $650^{\circ} \mathrm{C}$ & & $20^{\circ} \mathrm{C}$ & $650^{\circ} \mathrm{C}$ \\
\hline $\mathrm{Ti}_{3} \mathrm{Al}$ & - & 4,27 & - & - & - & 35500 & 27000 \\
\hline Super $-\alpha_{2}$, USA & $20-22$ & 4,7 & $160-220$ & $135-160$ & $2-6$ & 25100 & 21600 \\
\hline $\begin{array}{c}7115 \text { (Thermo- } \\
\text { hydrogen } \\
\text { treatment), } \\
\text { Russia }\end{array}$ & $3-4$ & 4,3 & $280-310$ & 180 & $2-3,5$ & 32500 & 24600 \\
\hline
\end{tabular}

Hydrogen processing technologies are being actively developed for these alloys - thermo-hydrogen treatment and hydrogen plasticization [2]. They allow to resolve the problem of technological plasticity and realize wider possibilities for controlling the structure and mechanical properties then traditional technology. Thus, Ti-14Al-3Nb-3V-0.5Zr alloy developed with the use of hydrogen technologies at operating temperature of $700^{\circ} \mathrm{C}$ is well deformed with hydrogen at temperatures of $850-900^{\circ} \mathrm{C}$. In specific strength properties it exceeds other alloys of this class («super $\alpha_{2}$ » type) due to the low content of «heavy» niobium and the formation of bimodal structures with optimal parameters as a result of thermo-hydrogen treatment [3].

Hydrogen technology of titanium alloys is based on the reversibility of the interaction of metals with hydrogen and those favorable in terms of technology effects that cause reversible alloying of titanium alloys with hydrogen. The reversibility of the interaction consists in the fact that the metals are relatively easy to absorb hydrogen in the vaporizing medium and just as easy to give it away in a vacuum. Hydrogen doping leads to the following effects, which can be used to improve technological processes: lowering the stresses of the metal flow, increasing the limiting degrees of deformation before the first crack, easy transformation of unfavorable microstructures into more favorable, improving the conditions of machining, strengthening adhesion. 
With hydrogen technology, it's possible to obtain deformed semi-finished products from the Ti-9Al-2Mo-1.5Zr alloy based on of $\alpha$-, $\alpha_{2}$ - and $\beta$ - phases applying the technologies that are used for industrial hot-resistant $(\alpha+\beta)$ - and pseudo- $\alpha$-alloys. Thermo-hydrogen treatment provides a creation of thermally stable structures by controlling release of $\alpha_{2}$-phase. It excludes an embrittlement at long-term operation temperatures and increases the crack resistance by increased work needed for crack initiation and changing of their development mechanism [4].

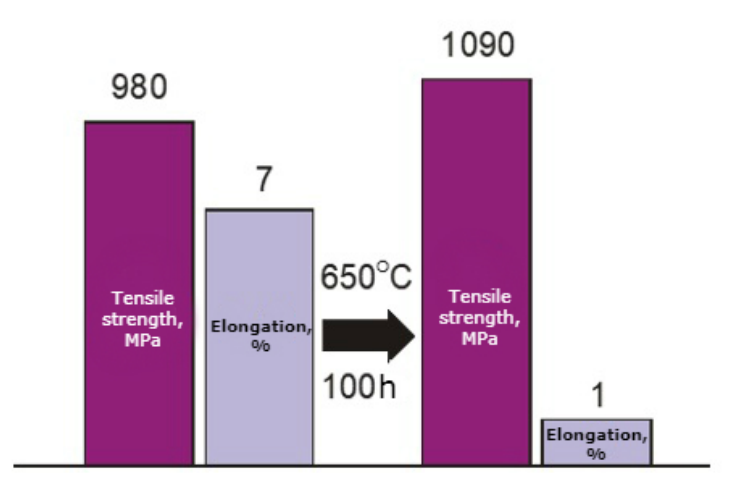

Standard heat treatment

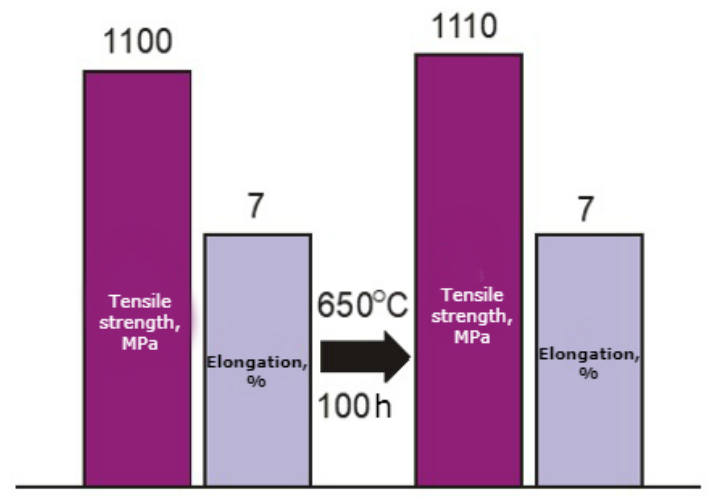

Thermohydrogen treatment

Pic.9 Hydrogen technology for production of composite materials based on titanium

Hydrogen processing technologies of VTI-4 ortho-alloy provide a reduction of deformation effort during the semi-finished products manufacture by $30-35 \%$ at temperatures of $900-950^{\circ} \mathrm{C}$, the achievement of strength over $1100 \mathrm{MPa}$ at plasticity to $7 \%$ [5].

Table 5. Hydrogen technologies of processing of alloy on the basis of Ti2AlNb

\begin{tabular}{|c|c|c|c|c|}
\hline \multirow{2}{*}{ Processing mode } & \multicolumn{4}{|c|}{ Mechanical properties at the room temperature } \\
\hline & $\mathrm{s}, \mathrm{MPa}$ & $\mathrm{s}_{0,2}, \mathrm{MPa}$ & $\mathrm{d}, \%$ & $\mathrm{y}, \%$ \\
\hline $\begin{array}{c}\text { Heat treatment: } 850^{\circ} \mathrm{C}, \\
12 \mathrm{~h} ., \text { air } \\
\end{array}$ & 1110 & 1010 & 3,0 & 6,0 \\
\hline $\begin{array}{c}\text { Thermo-hydrogen } \\
\text { treatment- } 1 \text { : } \\
\text { Hydrogen saturation } \\
\mathrm{C}_{\mathrm{H}}=0,2 \% ; \\
\text { Vacuum annealing : } \\
700^{\circ} \mathrm{C}, 8 \mathrm{~h} .\end{array}$ & 1190 & 1120 & 3,0 & 4,0 \\
\hline $\begin{array}{c}\text { Thermo-hydrogen } \\
\text { treatment- } 2 \text { : } \\
\text { Hydrogen saturation: } \\
\mathrm{C}_{\mathrm{H}}=0,2 \% ; \\
\text { Vacuum annealing: } 625^{\circ} \mathrm{C}, \\
4 \mathrm{~h} .+800^{\circ} \mathrm{C}, 4 \mathrm{~h} . \\
+850^{\circ} \mathrm{C}, 2 \mathrm{~h} .\end{array}$ & 1120 & 1020 & 7,0 & 9,0 \\
\hline
\end{tabular}

Complex technologies have been developed for treatment of implantable devices from Ti-6Al-4V and VT20 alloys, namely components of endoprosthesis of major joints, operating in terms of intensive friction and repeated loads [6].

Such technologies include thermo-hydrogen treatment and low temperature vacuum plasma nitriding. They create a high hardness submicrocrystalline structure in volume of item and deep (to $100 \mu \mathrm{m}$ ) gradient hardened by nitrogen layer. It virtually excludes a wear of titanium components during the use. The technology is used in mass production of endoprosthesis, which have long tame period of successful clinical usage. 

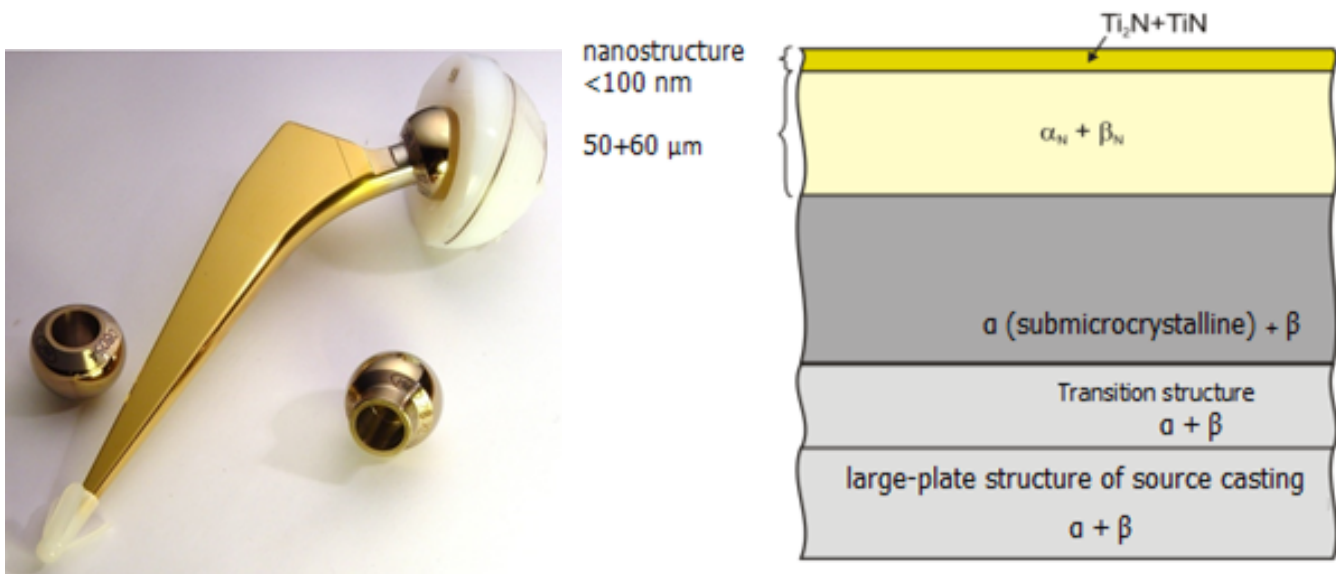

\section{Pic.10 Gradient surface structure of the hip endoprosthesis "SPHEN-C" after thermohydrogen treatment and vacuum ion-plasma nitriding (Ti-6Al-4V alloy)}

Thermohydrogen treatment is used for obtaining of porous material and osteointegrating coverage [7].

Fibers obtained by high-speed solidification of the melt with a transverse size of $20-50 \mu \mathrm{m}$ or standard wire with a diameter of $0.3-1.2$ $\mathrm{mm}$ made of commercially pure titanium are used as the starting material.

A desired configuration stock in the form of bars, sheets or coverages on monolithic base of titanium alloy is formed from them. This stock are subjected to diffusion bonding at temperatures of $800-950^{\circ} \mathrm{C}$ under slight pressure in order to keep desirable porosity. Then they are subjected to thermohydrogen treatment, during which they are filled with $0,6-0,8$ weight $\%$ of hydrogen at temperatures of 600 $800^{\circ} \mathrm{C}$, and then it is removed with vacuum annealing at the same temperatures. During introduction and removal of hydrogen, direct and reverse phase recrystallization occurs in the material, as a result of which the mechanical contact of fibers with each other or with a base becomes physical-and-chemical with general grain formation. It allows to significantly improve the mechanical properties of the porous material and its monolithic-based adhesion strength.

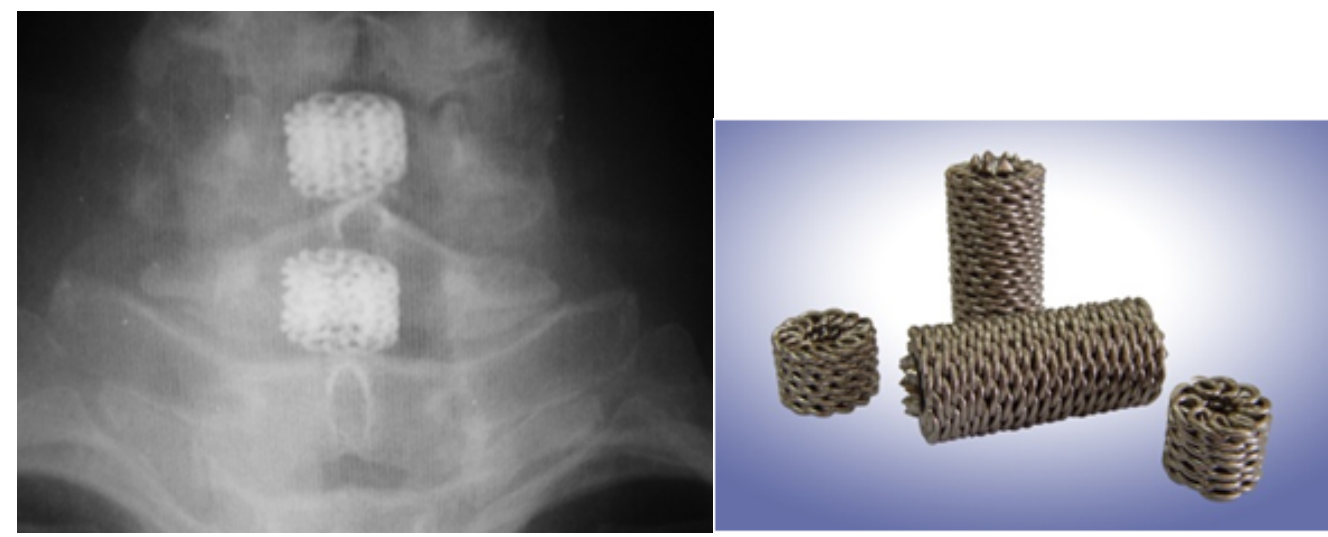

Pic.11 Clinical examples of use of porous titanium for prosthetics of vertebras

Now this technology is used for production of medical implants, for example, prosthetics of vertebral body and osteointegrate coverages on components of endoprosthesis of major joints. At the same time, it is possible to obtain the high porous titanium $(60-80 \%$ volume of porosity) with dimensions of through pores from 50 to $500 \mu \mathrm{m}$, that provides an intensive invasion of a bone into porous material or coverage and a secure retention of implant in a body.

It is attractive to use high-strength titanium alloys for single-acting constructions with shape memory effect. [8].

$(\alpha+\beta)$-alloys, that after the quenching have an a structure of martensite or metastable b-phase, can demonstrate a shape memory effect. Unlike with nickelide-based titanium alloys, they are characterized by less recoverable deformation (to $2 \%$ in comparison with $8 \%$ for $\mathrm{TiNi}$ ) and thermal instability of structure. It doesn't allow to use them in repeatedly acting constructions.

But in that time, reactive stresses in titanium alloys don't relax under cooling. It allows to use them for production of couplings for assembly of the pipelines. Couplings can be deformed and stored at room temperature, and the assembly of the compound can be carried out at short time reheating to $200-300^{\circ} \mathrm{C}$. Such compounds can be commissioned at temperatures from -100 to $+200^{\circ} \mathrm{C}$.

\section{$\underline{\text { Application }}$}

Creating of high tensile titanium alloys for marine facilities.

Experimental works continues on the creation of the high-strength titanium alloys for cases of vehicles for exploration and production of natural recourses from the bottom of the World Ocean, as well as for exploitation of marine transfer pipelines. 
Compositions of near $\beta$-titanium alloys are taken as base compositions that are used in aircraft industry: these are the VT22 and VST5553 alloys. In alloys of this class high strength can be reached with satisfying plasticity characteristics due to application of special modes of heat treatment. Hardening during the heat treatment is achieved due to the breakdown of solid $\beta$ - solution with separation of $\alpha-$ phase of certain dimensions. By now, due to adjustment of alloying of near $\beta$ - alloys of base composition, as well as the development of modes of gradual strengthening heat treatment, the new developed alloy was obtained for production of semi-finished products in the form of plates, forges and die forgings with satisfying set of standard mechanical properties. Preliminary experimental works on welding of developed composition of near $\beta$-titanium alloy showed that during the argon-arc and electron-beam welding there is a reduction of strength of weld metal and thermal impact zone. After the welding heat treatment allows to achieve a welded joint strength equal to 0.90.95 of tensile strength of base metal.

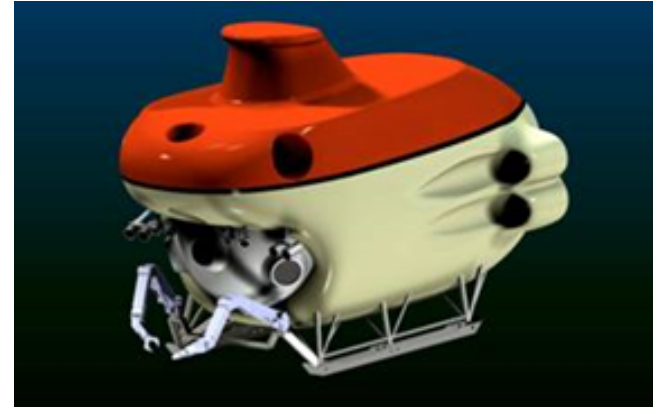

Pic.12 Deep-sea manned vehicle «Rift-1»,

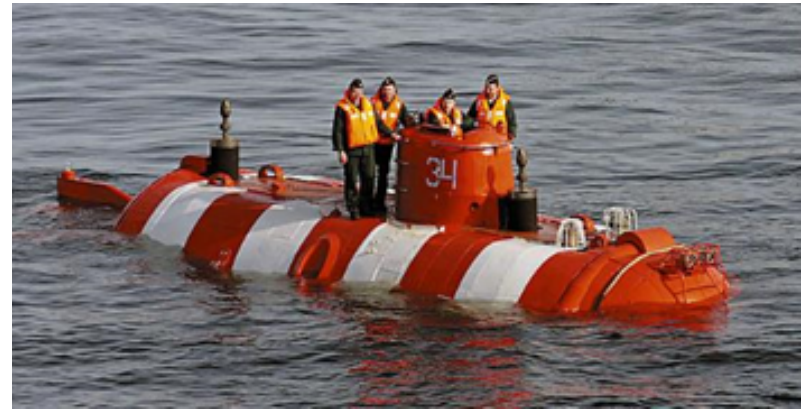

Pic. 13 Deep-sea rescue apparatus «Priz»

«Rift-2»

Creation of radiation-resistant alloy for nuclear energetics.

Works continue in the field of creation of the new class of radiation-resistant construction materials with accelerated breakdown of induced radioactivity instead of the steel for reactor vessels of low power. In comparison with steels, the use of titanium has a range of technical and economical advantages, such as a reduction of construction weight, exclusion of anticorrosive weld deposit, minimal environment impact, reduction of time prior to recycling of alloy after the end of its service life and etc. By now the chemical composition and manufacturing plan of radiation-resistant titanium alloy with tensile strength minimum $590 \mathrm{MPa}$ at temperature of $350^{\circ} \mathrm{C}$ was developed. The developed composition allows to provide a reduction of induced activity to the safe level during 30 years after completion of operation.

A technology has been developed for manufacturing low-power nuclear reactor vessel elements from cylindrical forgings or rolled ring blanks.

PM HIP technology presents here great perspectives due to the near net shape capabilities and much better UT inspectability of the PM HIPed parts, but requires the development of the largest HIP unit with about 4 meter diameter work space, that is now in considerqtion.

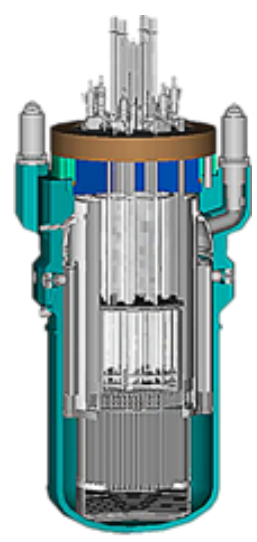

\section{Pic. 14 Transport reactor integrated type for perspective nuclear power station}

Developed alloy has a high resistance to corrosion in primary circuit environment_and radiation resistance at irradiation temperature up to $\mathrm{F}=3 \times 10^{20} \mathrm{n} / \mathrm{cm}^{2}$.

In Russia, for the first time in the world a project has been developed for a low power floating nuclear power unit, that represents a new class of nuclear energy sources. Power plants applying developed alloy can become a new basis for energetics of the regions of the Far North, the Far East, as well as serve oil and gas production, the Northern Sea Route and other hard-to-reach and extended areas and highways of Siberia. 
Expansion of the range of equipment made of titanium alloys for nuclear energy is associated with an increase in the efficiency of heattransfer elements. Currently, the Institute "Prometey" is working to improve the heat transfer performance of heat transfer equipment in two directions. The first direction is connected with the use of semi-finished products with developed surfaces, which include pipes with a ribbed surface and thin-plate panels. The second direction is connected with the development of an alloy for pipes with a high thermal conductivity in the radial direction. Technical titanium has the highest thermal conductivity in comparison with marine titanium alloys (PT-7M, PT-3V, 5V) but it also has low strength characteristics, especially at elevated temperatures. New titanium alloy along with high thermal conductivity has high characteristics of strength and heat resistance.

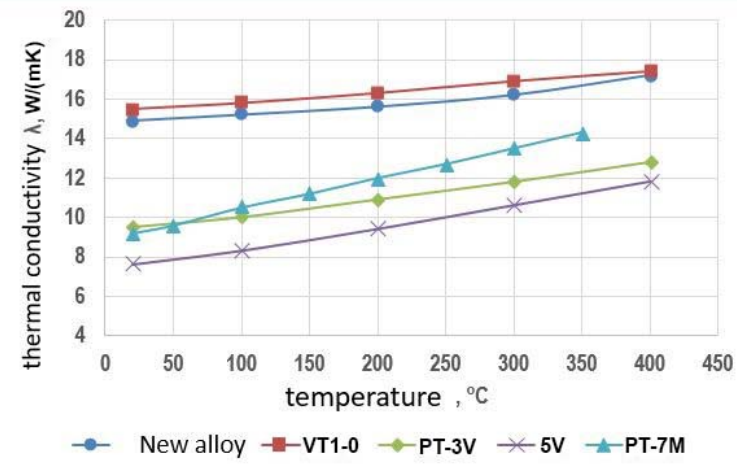

Pic. 15 The new titanium alloy thermal conductivity characteristics

Development of measures to reduce the titanium semi-finished products cost.

The works in fields of commercialization and cost reduction during the production of titanium and manufacture of constructions from them continue to remain relevant. Institute "Prometey" performs works to reduce the semi-finished products cost and improvement of manufacturing methods of finished items. The main ways to reduce the costs of semi-finished products are the use of the secondary materials in charge, lean alloying and the use of commercially effective technologies of production of ingots-slabs by the electron-beam remelting method and the formation of titanium stock by powder metallurgy.

As conclusions, we can provide statistics on the production of titanium mill products in the CIS countries and a forecast of titanium consumption in the domestic market in the coming years.

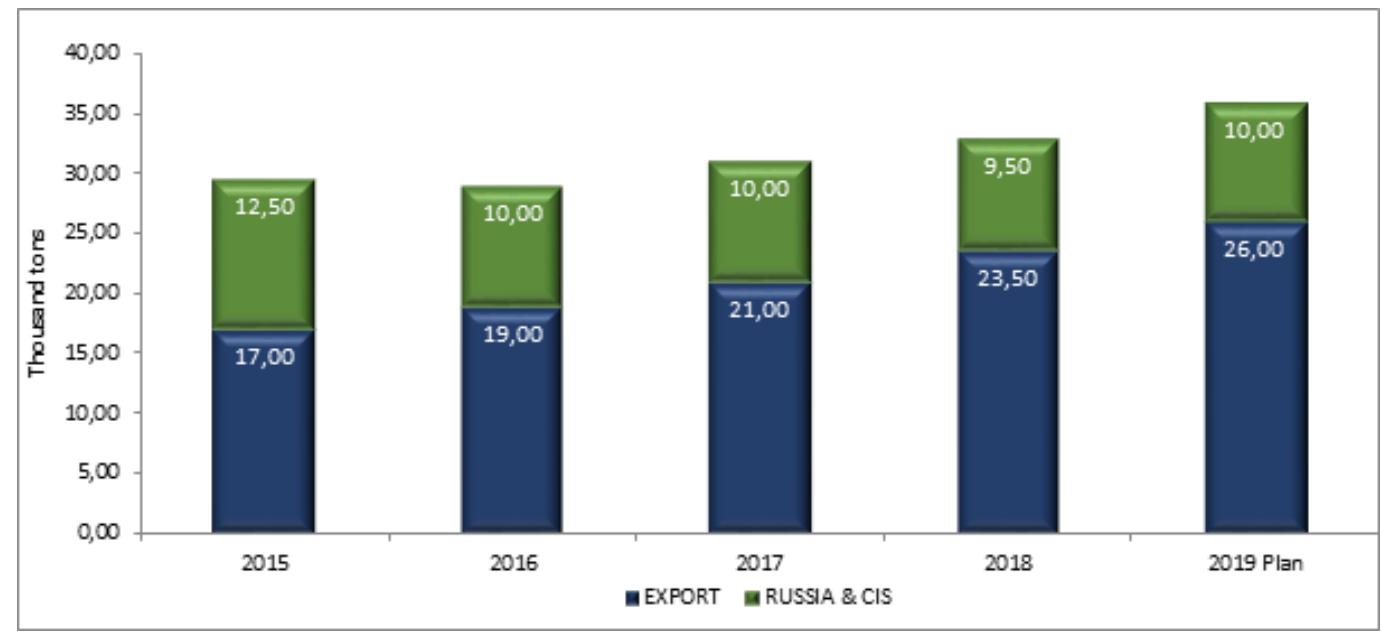

Pic. 16 Dynamic of shipments of Ti products

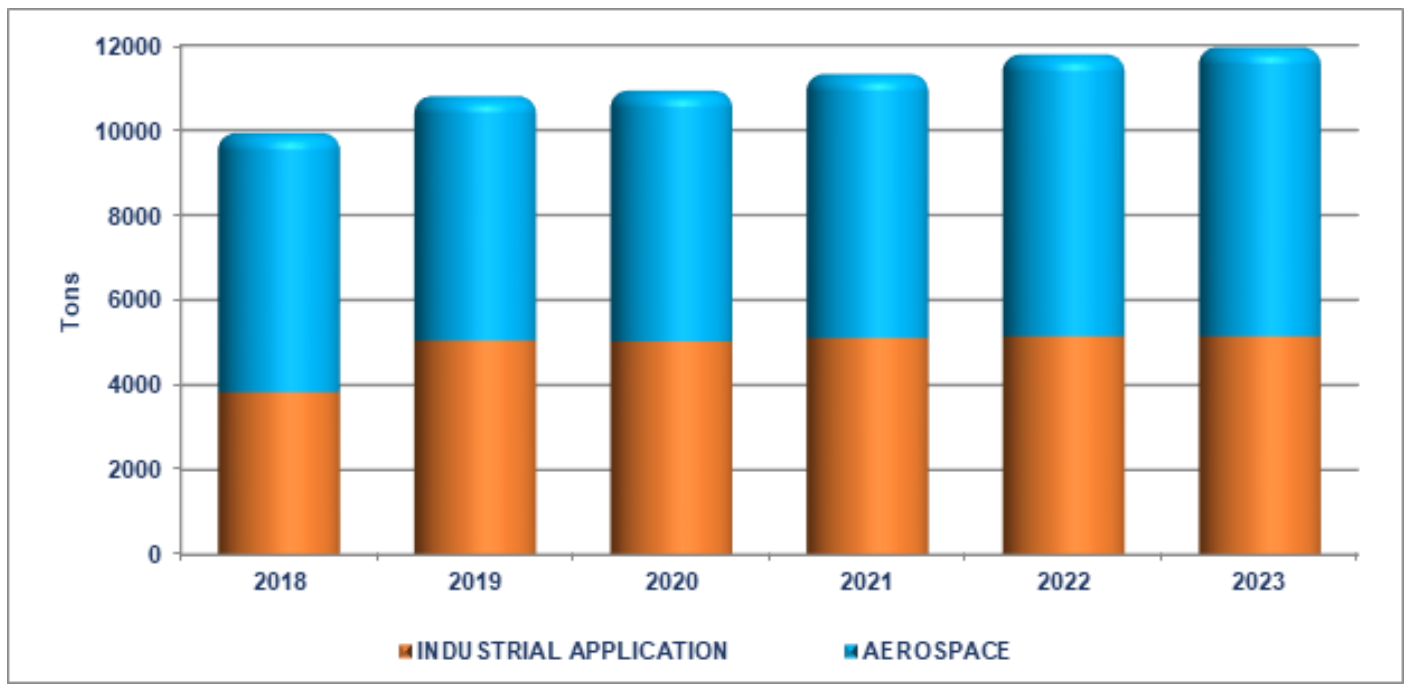

Pic. 17 Forecast of CIS market demand 


\section{Reference list.}

[1] Alexandrov A.V., Ziganshin A.G., Khudyakov D.A., Konshin R.S. Production of a lot of ingots with a diameter of $450 \mathrm{~mm}$ from highheat resisting alloy on the basis of titanium intermetallide of VTI-4 grade in JSC CHMP // Titanium (ISSN 2075-2903) - 2018 - № 3 - p. 33-39.

[2] Ilin A.A., Kolachev B.A., Nosov V.K., Mamonov A.M. Hydrogen technology of titanium alloys. MISIS, 2002 - 392 p.

[3] Mamonov A.M., Skvortsova S.V., Umarova O.Z., Agarkova E.O. Physicochemical and technological basics of formation of thermal stable structures of bimodal type in heat-resistant titanium alloys and titanium aluminide based alloys with reversible alloying with hydrogen // Titanium (ISSN 2075-2903) - 2013 - № 3 - p. 9-16.

[4] Mamonov A.M., Slezov S.S., Gvozdeva O.N. Control of phase composition, structure and complex of properties of high modulus titanium alloy by methods of thermohydrogen treatment // University news. Non-ferrous metallurgy. $-2018-$ № $1-$ p. 53-63.

[5] Skvortsova S.V., Il'in A.A., Nochovnaya N.A., Umarova O.Z. Structure and properties of semifinished sheet products made of an intermetallic refractory alloy based on Ti2AlNb // Materials Science, Vol. 51, № 6, May, 2016 (Ukrainian Original Vol. 51, № 6, November-December, 2015).

[6] Ilin A.A., Fedirko V.N., Mamonov A.M., Sarychev S.M., Chernyschova Yu.V. The impact of complex processing technologies on the structural state of the surface and the performance properties of medical implants made of titanium alloy VT6 // Titanium (ISSN 20752903) - 2014 - № 4 - p. 4-11.

[7] Kollerov M.Y., Shlyapin S.D., Senkevich K.S., Runova Y.E., Kazantsev A.A. Use of hydrogen heat treatment in the production of porous materials and objects made from titanium fiber and wire // Metallurgist. 2015 - T. 59 - № 3-4 - p. 241-247.

[8] Kollerov M.Y., Afonina M.B., Mamaev V.S., Sharonov I.A. Shape memory effect characteristics of a VT22i alloy // Russian metallurgy (Metally) 2010 - № 9 - p. 837-841. 